\title{
Nanosilica Enabled Reduction of Surfactant Adsorption in Porous Media under Reservoir Temperature and Salinity
}

\author{
Valery Khabashesku*, Oleksandr Kuznetsov, Devesh Agrawal, Radhika Suresh and Qusai Darugar \\ Center for Technology Innovation, USA
}

Submission: November 08, 2017; Published: November 21, 2017

*Corresponding author: Valery Khabashesku, Baker Hughes a GE Company, Center for Technology Innovation, Houston, TX, USA, Email: valery.khabashesku@bakerhughes.com

\begin{abstract}
Experiments with sandpack flow loop demonstrated that negatively charged nanosilica adsorbs onto a sand surface. Adsorbed nanoparticles passivate active sites on the formation rock and change the zeta-potential of the sand surface. Therefore, formation pre-treatment with negatively charged nanoparticles can reduce adsorption of anionic surfactant. The nanoparticles enable the surfactant molecules to penetrate farther into the formation and mobilize more oil rather than being lost because of retention. Sandpack experiments with sea water brine at $80{ }^{\circ} \mathrm{C}$ showed that nanoparticle pre-treatment of the sandpack reduced surfactant adsorption by a factor of 3. Experiments to study adsorption of nanoparticles and surfactants in various lithologies and its effect on subsequent oil recovery are instrumental for future applications and understanding of enhanced oil recovery (EOR).
\end{abstract}

Keywords: Surfactant adsorption; Silica nanoparticles; Enhanced oil recovery

\section{Introduction}

Adsorption of surfactants from aqueous solutions in porous media is very important in (EOR) from oil reservoirs because surfactant loss due to adsorption on the reservoir rocks impairs the effectiveness of the chemical solution injected to reduce the oil-water interfacial tension and renders the process economically unfeasible. Surfactant adsorption to solid-liquid interfaces is a process where transfer of surfactant molecules from a bulk solution phase to the solid-liquid interface takes place. The transfer can be considered as a partitioning of the adsorbate species between the interface and the bulk, and can occur if the interface is energetically favored by the surfactant in comparison to the bulk solution. In the presence of soil or sediment, adsorption of surfactant as monolayer may occur at low aqueous surfactant concentrations. With an increase in surfactant concentrations, surfactant monolayers adsorbed onto a solid surface begin to aggregate and form micelle-like structures called admicelles or hemimicelles, depending on whether the aggregates have one or two surfactant layers. When these structures form on a solid surface, adsorption of additional surfactant may rapidly increase until a complete bilayer of surfactant covers the solid surface. A number of studies have been recently dedicated to surfactant adsorption [1-5] with a few related to nanoparticle applications to reduce surfactant losses [6,7]. However, nanoparticle-surfactant systems were studied at room temperature using only fresh water. Practical EOR applications involve temperatures as high as $70-100{ }^{\circ} \mathrm{C}$ and hard brine conditions. Therefore, our research work focuses on reservoir conditions typical to the Gulf of Mexico shelf, with reservoir temperatures around $80^{\circ} \mathrm{C}$ and sea water used as injection brine.

\section{Methodology}

Surfactant adsorption experiments were carried out in a sandpack of 20/40 sand that was compacted for each test using the same procedure. Experiments in such well-defined porous media avoid difficulties related to the variability of lithology, pore size, permeability, etc., which can play defining role in surfactant adsorption. Each sandpack column contained $200 \mathrm{~g}$ of sand compressed at 1000 psi. The column was prepared by compressing $20 \mathrm{~g}$ of sand in a single iteration. Pore volume for the sandpack column was found to be $40 \mathrm{ml}$ consistently for all experiments. 


\section{Recent Advances in Petrochemical Science}

Preliminary tests indicated that a flow rate of $1 \mathrm{ml} / \mathrm{min}$ is optimal to reach uniform saturation of the sandpack with injecting fluids. For the same reason, a back pressure of 5psi was applied during the injection to restrict the flow and force the fluid into the bulk of sandpack. Surfactant and nanoparticle concentrations were kept constant for all experiments at approximately $5000 \mathrm{ppm}$. This steady concentration enabled reliable detection of surfactant and nanoparticles in the effluent.

Each experiment began with injection of artificial sea water (ASW) to saturate the core and check for any leaks. Next, the sandpack was enclosed into a heating jacket to set the temperature at $80^{\circ} \mathrm{C}$. Once a steady flow and back pressure across the sandpack column was established, the test fluid was injected for 2.4 pore volumes (PV), followed by the injection of ASW for another 2.6PV. Effluent was collected with the autosampler in a $10 \mathrm{ml}$ bottles. Usually, $8 \mathrm{ml}$ of effluent is collected in each bottle.

A Malvern Nano Zeta-sizer (DLS) was found to be instrumental in measuring the concentration of nanosilica particles by observing the count rate. A new method was developed to measure surfactant concentration in the effluent samples. This method enables reliable detection of surfactant from organics-free fluid at concentrations as low as $250 \mathrm{ppm}$. First, a fluid from effluent sample was dried using a freeze- dry system. Freeze-drying completely removes the aqueous phase under the same conditions from all samples, leaving behind solids from sea water brine salts and surfactant mixed in the form of fine powder that is easy to handle. Next, thermo gravimetric analysis (TGA) was used to determine the weight loss due to surfactant decomposition. Surfactant decomposition occurred at temperatures between $200-400^{\circ} \mathrm{C}$. No other peaks were found in the same area for salts obtained by freeze-drying brine. Weight measurements were taken for the initial liquid sample and the freeze-dried sample. The TGA instrument was calibrated for surfactant calibration measurements.

\section{Surfactant adsorption in artificial sea water brine}

Sasol's alkylbenzene sulfonate-Soloterra 172(S172) dispersed in ASW was injected into a sandpack column. The concentration of surfactant for each effluent sample is plotted in Figure 1. The black dotted line indicates the surfactant concentration in the injection fluid during the experiment. The time event at 3.6PV (highlighted in red) indicates the moment when the water injection pushed out all surfactant from the sandpack column. At that moment no surfactant remained in the solution. The remaining surfactant that was pushed out of the sandpack could have been related to the surfactant desorbing from the sand surface potentially because of osmotic pressure.

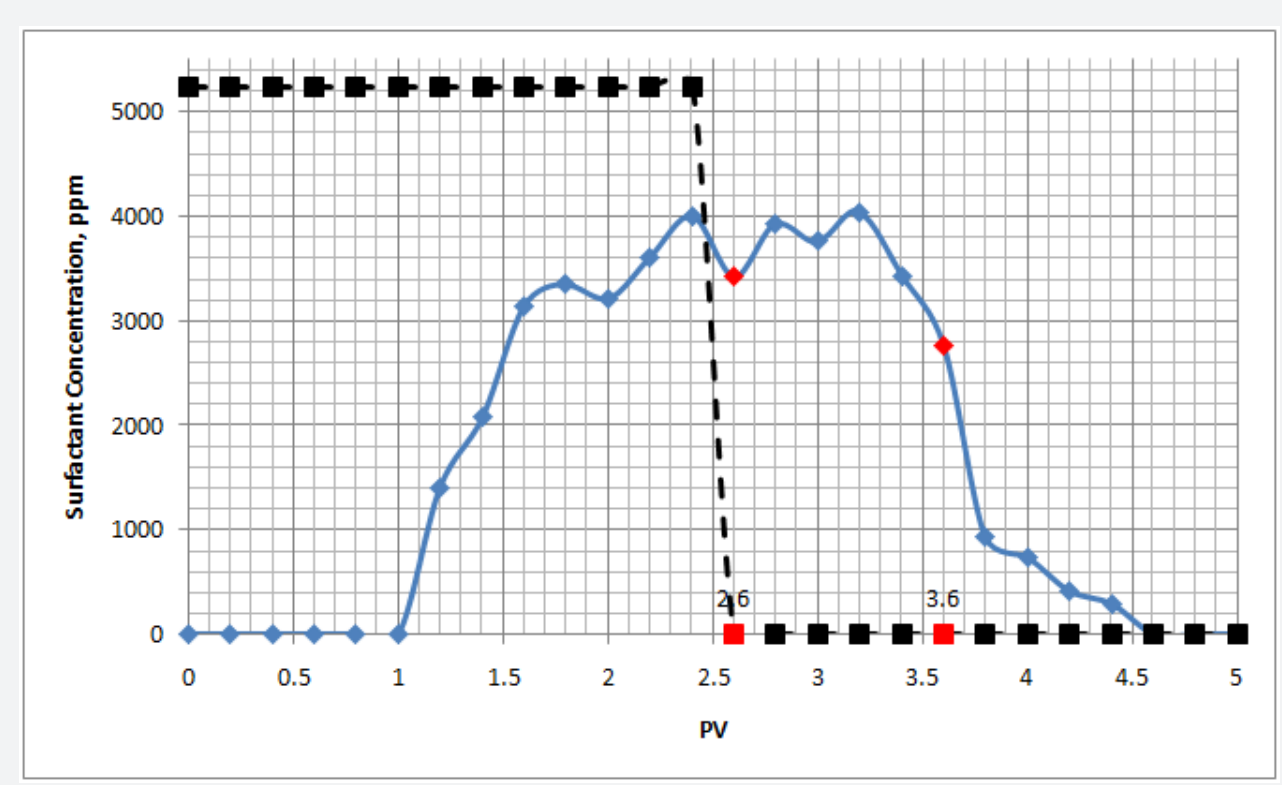

Figure 1: Surfactant concentration in the effluent (blue line) and surfactant injection concentration (black dotted line). Experiment performed with ASW.

Surfactant adsorption can be calculated as the difference between total surfactant injected up to 3.6PV and surfactant collected by this same point. Overall, approximately $504 \mathrm{mg}$ of surfactant was injected while $342 \mathrm{mg}$ collected. Because the total weight of the sand column was $200 \mathrm{~g}$, the adsorption was approximately $0.810 \mathrm{mg} / \mathrm{g}$ of rock. Adsorption of the surfactant in ASW was much higher than in DIW. This can be explained by presence of divalent cations that bridge the surfactant polar heads to the sand surface. 


\section{Recent Advances in Petrochemical Science}

\section{Nanoparticle adsorption in artificial sea water brine}

A similar experiment was carried out using negatively charged Levasil nanosilica dispersed in sea water brine. The concentration of nanoparticles was measured using a Malvern Nano Zeta-Sizer. The concentration of injected suspension was prepared at $5000 \mathrm{ppm}$, but DLS measurements indicated a concentration of $4711 \mathrm{ppm}$. In addition to the count rate, the zeta-average size was recorded. Effluent carries some of the fines from the sand, contributing to the count rate. Pure nanoparticle suspension average size was $23.65 \mathrm{~nm}$. Consequently, the count rate with the corresponding average size of above $23 \mathrm{~nm}$ should be disregarded because it was related to the fines. Overall, the contribution to the count rate from the sand fines was minimal.

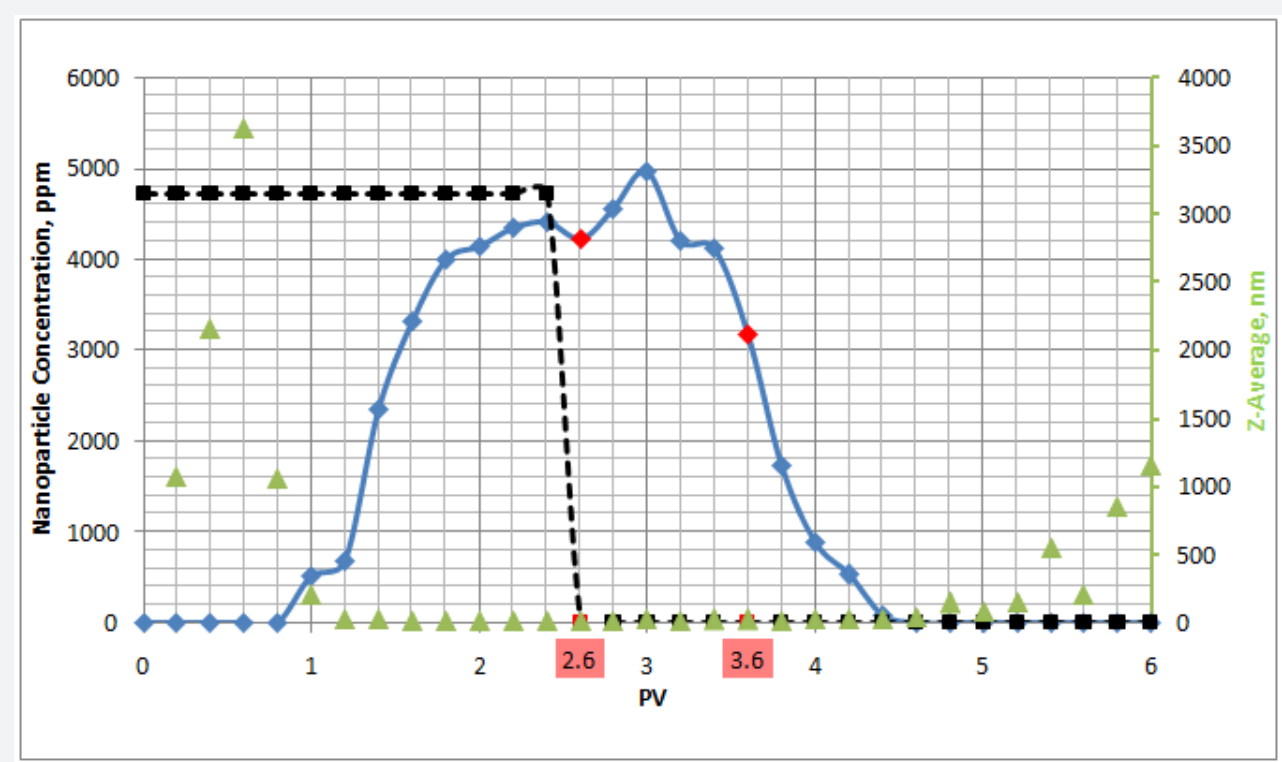

Figure 2: Nanoparticle concentration in effluent (blue line), injection fluid (black dotted line) and the size of particles in the effluent (green markers).

Figure 2 shows the concentration measurements for the nanoparticle effluent (blue line); nanoparticle concentration in the injection fluid is indicated with black dotted line. Both concentrations are plotted on the left axis, while right axis reports the average size of particles in each corresponding sample. Size data are shown with green triangle markers.

Similar to surfactant injection experiment, nanoparticles were injected up to the point at $2.6 \mathrm{PV}$, followed with the sea water brine injection for another $3.4 \mathrm{PV}$. At $3.6 \mathrm{PV}$, all free nanoparticles had been pushed from the sandpack column. The adsorption was measured as a difference in the weight of nanoparticles injected and collected up to the 3.6PV. The amount of injected nanoparticles was found to be $452 \mathrm{mg}$, collected $-392 \mathrm{mg}$, resulting in $0.3 \mathrm{mg} / \mathrm{g}$ of rock adsorption. No precipitation or aggregation of nanoparticles was observed in this experiment.

\section{Surfactant adsorption after nanoparticle treatment}

To study the effect of nanoparticles on surfactant adsorption, Levasil nanosilica was injected in the sandpack, followed by the injection of S172 surfactant. The idea was to adsorb nanoparticles at all active sites of the sand, and/or lower the zeta-potential of the sand surface so fewer surfactant molecules would be retained in the porous media. The sandpack was prepared in the same way as for the previous experiment. ASW was injected until pressure and flow rate stabilized at 80 ${ }^{\circ} \mathrm{C}$. The same flow rate for the injection was used as previously: $1 \mathrm{ml} / \mathrm{min}$. Next, nanosilica, dispersed in ASW at concentration $5150 \mathrm{ppm}$, was injected into a sandpack for 2.4 pore volumes $(1 \mathrm{PV}=40 \mathrm{ml})$. Nanoparticle concentration and zeta-average size measured with the DLS (Malvern Nanosizer) is shown in Figure 3. Because concentration measurements were based on count rate, the presence of surfactant makes it impossible to determine the concentration of nanoparticles as the count rate changes with little or no correlation with the nanoparticle concentration. Therefore, concentration measurements of nanoparticles at a pore volume of 3.4 are not reliable. In addition, the zeta-average measured after this point is 3 times higher than the average particle size $(63.7 \mathrm{nmvs} .23 \mathrm{~nm})$, suggesting that the nanoparticle concentration was insignificant. Overall, approximately $495 \mathrm{mg}$ of nanoparticles were injected into the sandpack during this experiment and $422 \mathrm{mg}$ recovered. Nanoparticle adsorption, based on these numbers, was $0.364 \mathrm{mg} / \mathrm{g}$ of rock. 


\section{Recent Advances in Petrochemical Science}

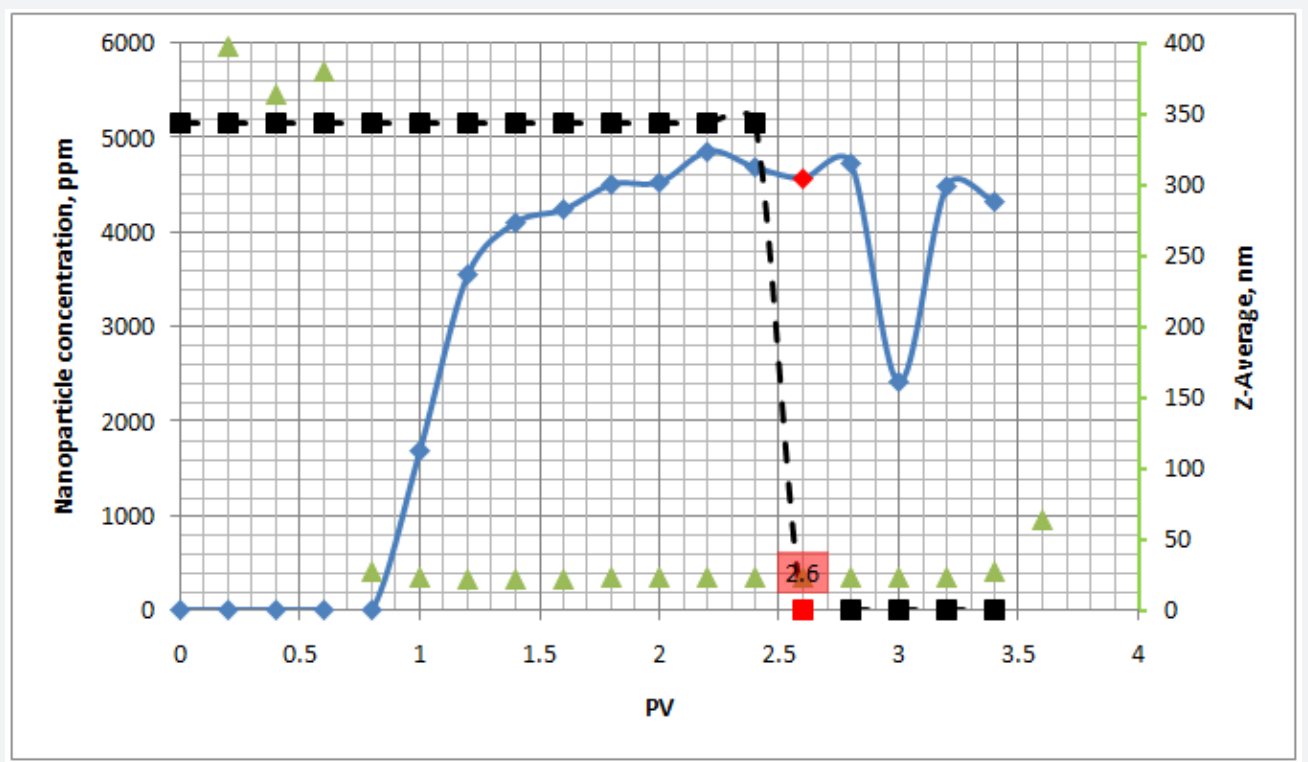

Figure 3: Nanoparticle concentration in effluent (blue line), injection fluid (black dotted line) and the size of particles in the effluent (green markers).

Surfactant S172 was injected into the same sandpack right after the nanoparticle injection. The surfactant was injected at the same conditions as in the previous experiments: flow rate $1 \mathrm{ml} / \mathrm{min}$, a temperature of $80^{\circ} \mathrm{C}$ in the ASW for 2.4 pore volumes. The concentration of recovered surfactant is plotted in Figure 4. The black dotted line indicates the $5400 \mathrm{ppm}$ surfactant concentration in the injection fluid. The total amount of surfactant injected in this experiment was $519 \mathrm{mg}$, with $466 \mathrm{mg}$ recovered. Surfactant retention was found to be $0.265 \mathrm{mg} / \mathrm{g}$ of rock, which was at least 3 times less than the surfactant retention without nanoparticle pre-treatment $(0.810 \mathrm{mg} / \mathrm{g})$. Therefore, nanoparticles are capable of reducing surfactant adsorption onto the sandstone surface.

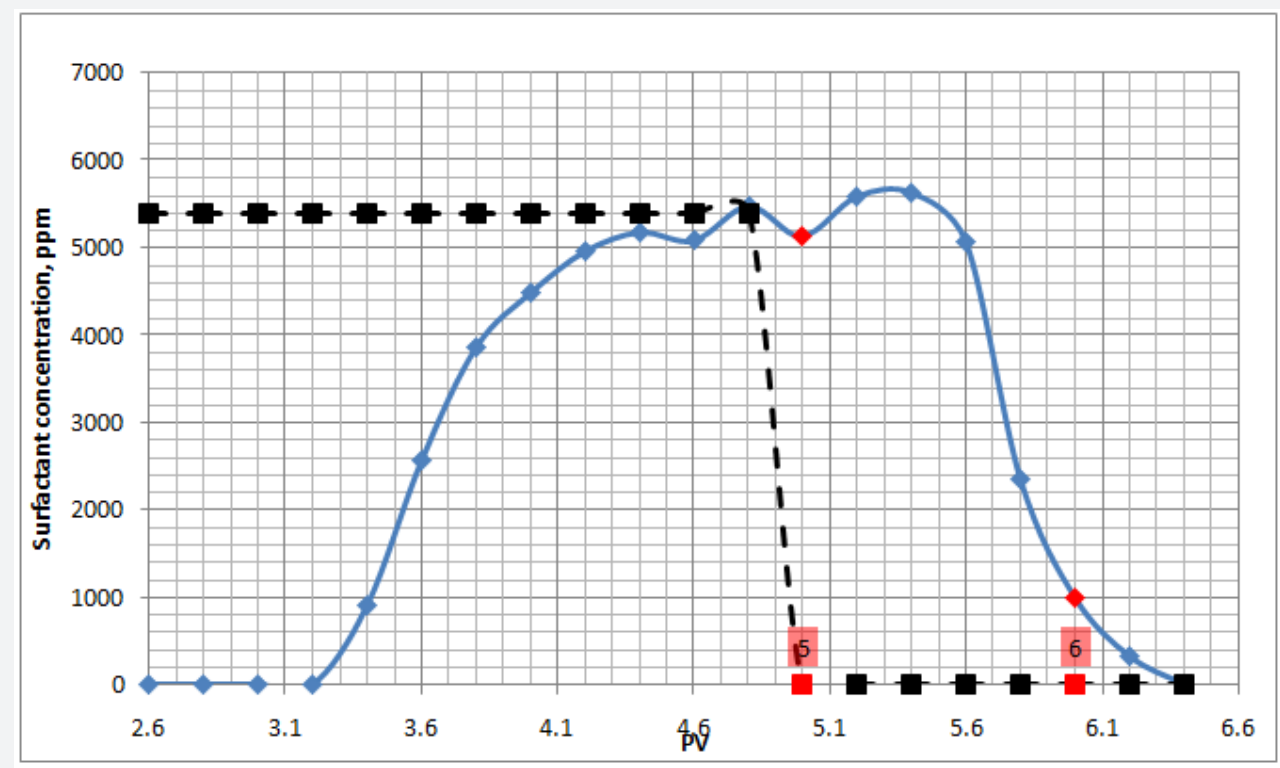

Figure 4: Surfactant concentration in the effluent (blue line) and surfactant injection concentration (black dotted line).

\section{Conclusion}

Comprehensive experimental program enablean improved understanding of nanoparticle and surfactant transport through porous media. All experimental data were obtained using an in-house built sandpack flow loop. The test data show that negatively charged silica nanoparticles can reduce anionic surfactant retention in the porous media by at least 3 times. 


\section{References}

1. Shamsi Jazeyi H, Hirasaki GJ, Verduzco R (2013) Sacrificial agent for reducing adsorption of anionic surfactants. SPE international symposium on oilfield chemistry, Woodlands, Texas, USA. pp. 1-16.

2. Li K, Jing X, He S, Wei B (2016) Static adsorption and retention of viscoelastic surfactants in porous media: EOR implications. Energy \& Fuels 30(11): 9089-9096.

3. Jang SH, Liyanage PJ, Tagavifar M, Chang L, Upamali KAN, et al. (2016) A Systematic method for reducing surfactant retention to extremely low levels. SPE improved oil recovery conference, Tulsa, Oklahoma, USA pp. 1-33.
4. Sharma H, Lu J, Weerasooriya UP, Pope GA, Mohanty KK, et al. (2016) Adsorption in chemical floods with ammonia as the alkali. SPE improved oil recovery conference, Tulsa, Oklahoma, USA. pp. 1-15.

5. Zhang J, Wang D, Olatunji K (2016) Surfactant adsorption investigation in ultra-low permeable rocks. SPE low perm symposium, Denver, Colorado, USA. pp. 1-7.

6. Rahimi Kh, Adibifard M (2015) Experimental study of the nanoparticle effect on surfactant absorption and oil recovery in one of the iranian oil reservoirs. J Pet Sci Technol 33(1): 79-85.

7. Wu Y, Chen W, Dai C, Huang Y, Li H, et al. (2017) Reducing surfactant adsorption on rock by silica nanoparticles for enhanced oil recovery. Journal of Petroleum Science and Engineering 153: 283-287.

\begin{tabular}{l} 
Your next submission with Juniper Publishers \\
will reach you the below assets \\
- Quality Editorial service \\
- Swift Peer Review \\
- Reprints availability \\
- E-prints Service \\
- Manuscript Podcast for convenient understanding \\
- Global attainment for your research \\
- Manuscript accessibility in different formats \\
( Pdf, E-pub, Full Text, Audio) \\
- Unceasing customer service \\
Track the below URL for one-step submission \\
https://juniperpublishers.com/online-submission.php \\
\hline
\end{tabular}

